PREPARED FOR THE U.S. DEPARTMENT OF ENERGY, UNDER CONTRACT DE-AC02-76CH03073

PPPL-3668

PPPL-3668

UC-70

Neutral Particle Analyzer Measurements of Ion Behavior in NSTX

by

S.S. Medley, R.E. Bell, D.S. Darrow, and A.L. Roquemore

February 2002

NM|

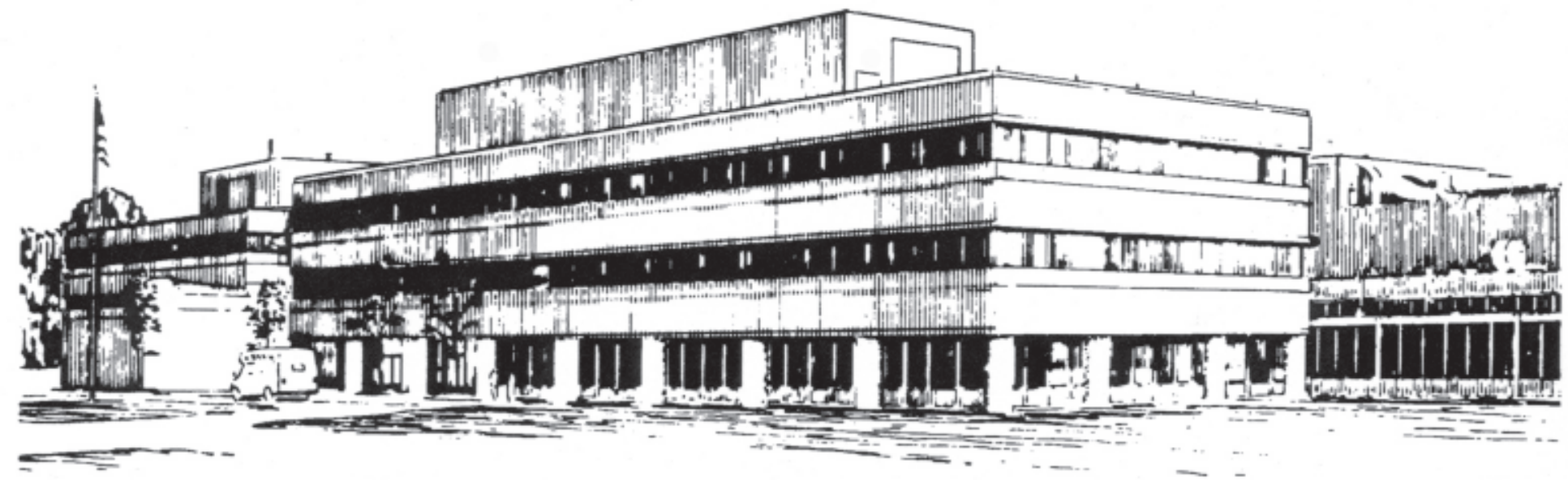

PRINCETON PLASMA PHYSICS LABORATORY PRINCETON UNIVERSITY, PRINCETON, NEW JERSEY 


\section{PPPL Reports Disclaimer}

This report was prepared as an account of work sponsored by an agency of the United States Government. Neither the United States Government nor any agency thereof, nor any of their employees, makes any warranty, express or implied, or assumes any legal liability or responsibility for the accuracy, completeness, or usefulness of any information, apparatus, product, or process disclosed, or represents that its use would not infringe privately owned rights. Reference herein to any specific commercial product, process, or service by trade name, trademark, manufacturer, or otherwise, does not necessarily constitute or imply its endorsement, recommendation, or favoring by the United States Government or any agency thereof. The views and opinions of authors expressed herein do not necessarily state or reflect those of the United States Government or any agency thereof.

\section{Availability}

This report is posted on the U.S. Department of Energy's Princeton Plasma Physics Laboratory Publications and Reports web site in Fiscal Year 2002. The home page for PPPL Reports and Publications is: http://www.pppl.gov/pub_report/

DOE and DOE Contractors can obtain copies of this report from:

U.S. Department of Energy

Office of Scientific and Technical Information

DOE Technical Information Services (DTIS)

P.O. Box 62

Oak Ridge, TN 37831

Telephone: (865) 576-8401

Fax: (865) 576-5728

Email: reports@adonis.osti.gov

This report is available to the general public from:

National Technical Information Service

U.S. Department of Commerce

5285 Port Royal Road

Springfield, VA 22161

Telephone: 1-800-553-6847 or

(703) 605-6000

Fax: (703) 321-8547

Internet: http://www.ntis.gov/ordering.htm 


\title{
Neutral Particle Analyzer Measurements of Ion Behavior in NSTX
}

\author{
S. S. Medley, R. E. Bell, D. S. Darrow and A. L. Roquemore \\ Princeton Plasma Physics Laboratory, P. O. Box 451, Princeton, NJ 08543 USA
}

\begin{abstract}
Initial results obtained with the Neutral Particle Analyzer (NPA) diagnostic on the National Spherical Torus Experiment (NSTX) are presented. Magnetohydrodynamic activity and reconnection events cause depletion of the deuterium energetic ion distribution created by neutral beam injection. Adding High Harmonic Fast Wave Heating to neutral beam heated discharges results in the generation of an energetic ion tail above the beam injection energy. NPA measurements of the residual hydrogen ion temperature are in good agreement with those from recombination spectroscopy.
\end{abstract}

\section{Introduction}

The National Spherical Torus Experiment (NSTX) is a low aspect ratio $(R / a \sim 1.3)$ device with auxiliary heating from Neutral Beam Injection (NBI) and High Harmonic Fast Wave (HHFW) heating. Typical NSTX parameters are $R_{0}=85 \mathrm{~cm}, a=67 \mathrm{~cm}, I_{p}=0.7-$ 1.4 MA, $B_{f}=0.25-0.45 \mathrm{~T}$. Three co-directed deuterium neutral beam sources have injected $P_{N B} \leq 4.7 \mathrm{MW}$. HHFW heating typically has delivered $P_{R F} \leq 3 \mathrm{MW}$ to $\mathrm{D}$ and He plasmas. Important to the understanding of ion behavior in NSTX are the Neutral Particle Analyzer (NPA) diagnostics and the Charge Exchange Recombination Spectroscopy (CHERS) system. The NPA diagnostic utilizes a PPPLdesigned $E \| B$ spectrometer [1] which measures the energy spectra of $\mathrm{H}^{+}$and $\mathrm{D}^{+}$ion species simultaneously with a time resolution of $\sim 1 \mathrm{msec}$ set by signal-to-noise levels. The calibrated energy range is $\mathrm{E}=0.5-150 \mathrm{keV}$ and the energy resolution varies from $\Delta \mathrm{E} / \mathrm{E}$

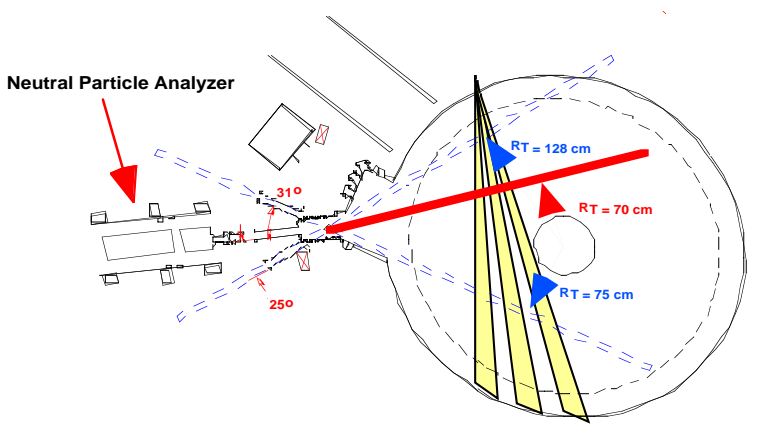

Figure 1. Neutral Particle Analyzer layout on NSTX. $=7 \%$ at low $\mathrm{E}$ to $\Delta \mathrm{E} / \mathrm{E}=3 \%$ at high $\mathrm{E}$.

The detector consists of a large area microchannel plate (MCP) which is provided with two rectangular, semi-continuous

S. S. Medley, et al. Contributed Paper to IAEA TCM on Energetic Particles in Magnetic Confinement Systems, Göteborg, Sweden, October 8-11, 2001 
active area strips, one coinciding with each of the mass rows for detection of $\mathrm{H}^{+}$and $\mathrm{D}^{+}$and each mass row has 39 energy channels. The NPA measures Maxwellian spectra of residual $\mathrm{H}^{+}$to obtain ion temperatures, $\mathrm{T}_{\mathrm{i}}$, and $\mathrm{D}^{+}$energetic ion spectra produced by injection of 80 $\mathrm{keV} \mathrm{D}$ neutral beams into a D plasma. The CHERS system [2] measures carbon ion temperature, $T_{i}$, and toroidal flow, $V_{f}$, at 17 radial positions spanning the outer half of the minor radius with $20 \mathrm{~ms}$ time resolution during NBI.

The three neutral beam lines on NSTX inject at $R_{\tan }$ of $50 \mathrm{~cm}$ (source A), $60 \mathrm{~cm}$ (source B) and $70 \mathrm{~cm}$ (source C). Initially, the NPA was installed with a fixed sightline having $R_{\tan }=$ $70 \mathrm{~cm}$ which views across the neutral beam lines at co-directed ions as shown by the solid chord in Figure 1. At present, the NPA is being upgraded to provide horizontal scanning as shown by the dashed chords as well as vertical scanning to view below the plasma midplane.

A rich variety of energetic ion behavior resulting from MHD activity has been observed in NSTX during experiments conducted during the last year and some interesting examples are presented in this paper.

\section{Effect of MHD Activity on NPA Energetic lon Measurements}

The appearance of magnetohydrodynamic (MHD) activity can have a pronounced effect on both the 'thermal' ( $\mathrm{E} \sim 0.5-5 \mathrm{keV}$ ) and 'energetic' $(\mathrm{E} \sim 5-80 \mathrm{keV})$ ion populations in

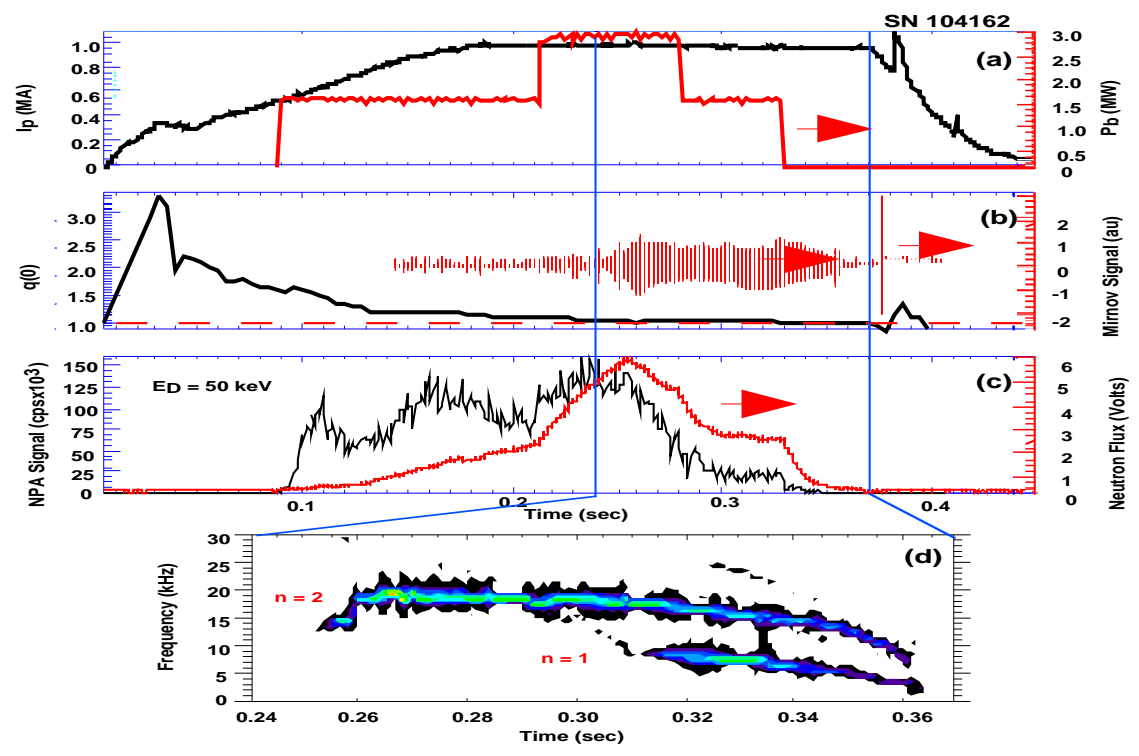

Figure 2. MHD activity (panels b,d) causes losses in neutron yield and energetic deuterium ion confinement (panel c) in NSTX

S. S. Medley, et al. Contributed Paper to IAEA TCM on Energetic Particles in Magnetic Confinement Systems, Göteborg, Sweden, October 8-11, 2001 
NSTX. An example is presented in Figure 2 where panel (a) shows injection of a peak NB power of $3 \mathrm{MW}$ during the $1 \mathrm{MA}$ flat top of a deuterium discharge. Panel (b) shows the onset of large scale MHD activity at $t \sim 0.26 \mathrm{sec}$ as indicated by the Mirnov coil measurements. Note that $q(0)>1$ during this MHD activity. As shown in panel (d), this activity is identified as a large $\mathrm{n}=2$ mode with frequency $\sim 20 \mathrm{kHz}$ arising at $0.26 \mathrm{sec}$ followed by an additional $\mathrm{n}=$ 1 mode with frequency $\sim 10 \mathrm{kHz}$ at $0.32 \mathrm{sec}$. For both modes the frequency downshifts during the period of activity. Onset of the $n=2$ mode leads to rollover and relatively slow decay of the energetic ion population and consequently the neutron yield as shown in panel (c). Although not shown here, thermal ions are also lost during MHD activity which results in a collapse in the ion temperature.

\section{Effect of Reconnection Events on Thermal and Energetic Ion Distributions}

The effects of reconnection events and sawteeth on the thermal and energetic ion distributions in NSTX differ from that observed for MHD activity. In this case, prompt loss of the energetic ions occurs on a fast time scale of $\leq 2 \mathrm{msec}$ while the thermal ions remain confined but are redistributed outboard from the plasma core to a region of higher neutral
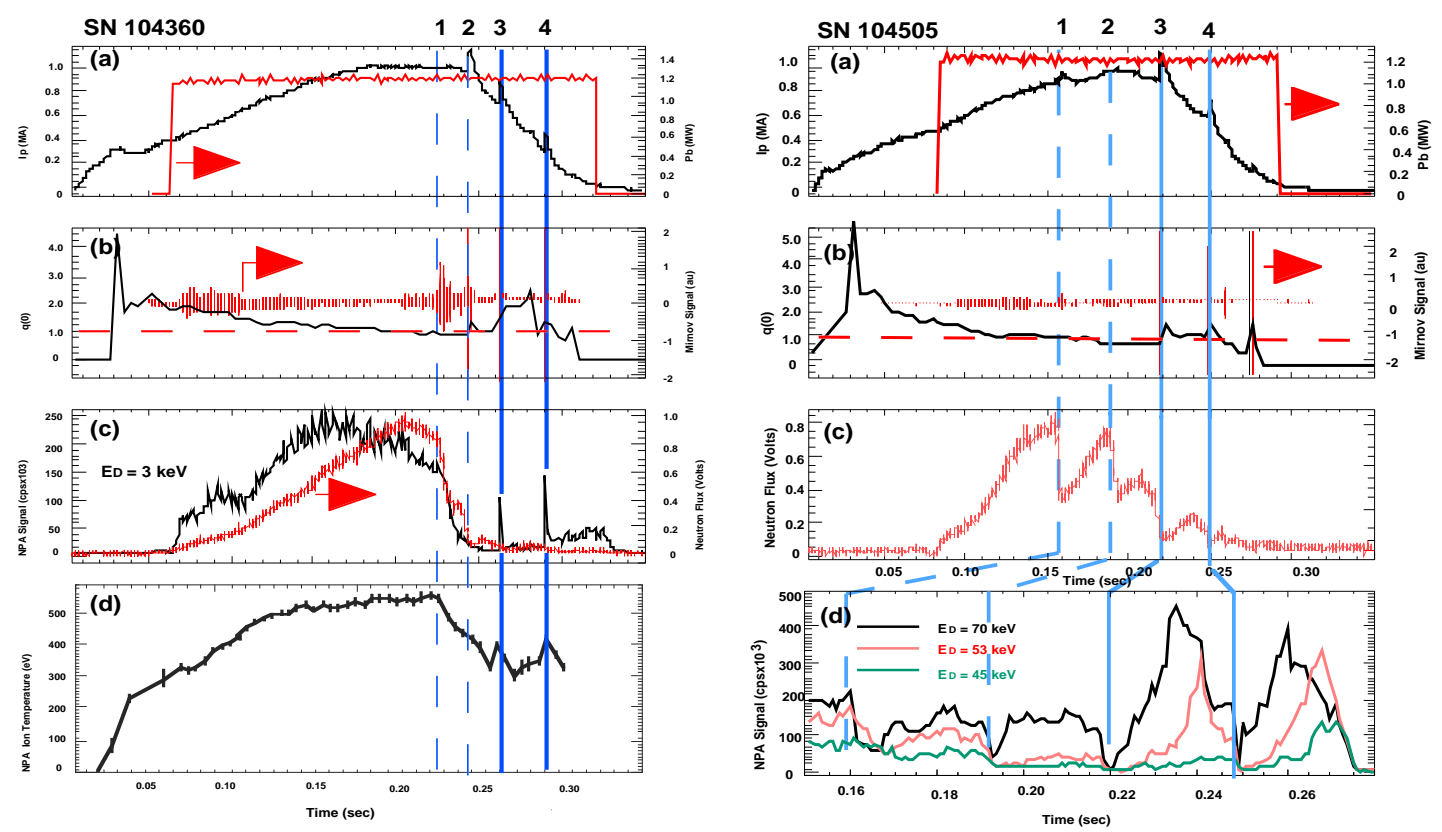

Figure 3. Illustration of the effect of reconnection events on thermal (left) and energetic ion (right) ion distributions measured by the NPA diagnostic in NSTX

S. S. Medley, et al. Contributed Paper to IAEA TCM on Energetic Particles in Magnetic Confinement Systems, Göteborg, Sweden, October 8-11, 2001 
density which leads to a burst in the neutral particle flux and the apparent ion temperature measured by the NPA. These effects are illustrated in Figure 3 which shows the case for the 'thermal' ions on the left and 'energetic' ion on the right. Panels (a) give waveforms for the plasma current and total injected beam power. Reconnection events (REs) are signatured by sharp upticks on the plasma current waveform which are flagged by the solid vertical lines in both plots. Panels (b) show representative Mirnov coil traces in which an RE is identified by a sharp signal burst while other activity exhibits more continuous signal fluctuations. In both plots, strong REs are preceded by sawteeh or other MHD activity flagged by the dashed vertical lines. While this preceding activity does influence neutron and ion behavior, attention will be focused on the strong REs marked by the solid vertical lines. In the case of the thermal ions (left), an RE produces a sharp burst in the NPA signal [panel (c)] while having little or no affect on the neutron yield. A small increase in the apparent ion temperature can be seen in panel (d). These observations are indicative of a redistribution of core ions to the plasma periphery where the neutral density is higher, thus producing the spike in the NPA flux and measured $T_{i}$. On the other hand, an RE causes a prompt depletion of the NPA energetic ion distribution [right, panel (d)] without the redistribution signature seen in the thermal energy range. The ion loss caused by the RE results in a prompt drop in the neutron yield as seen in panel (c). As neutral beam injection continues following the REs, the energetic ion distribution recovers as does the neutron yield. The NPA signal becomes larger during $I_{p}$ rampdown due to the increasing charge exchange neutral target density.

\section{NPA Measurements of HHFW Energetic Tail Formation}

High Harmonic Fast Wave (HHFW) heating at $30 \mathrm{MHz}, P_{R F} \leq 3 \mathrm{MW}$ has been applied to NSTX plasmas with and without the presence of NB heating. When HHFW is combined with NB heating, an energetic tail up to $140 \mathrm{keV}$ is formed above the $\mathrm{D}$ neutral beam injection energy which is typically $\sim 80 \mathrm{keV}$. An example of this behavior is shown in Figure 4. From the top, the waveforms on the right show the plasma current with a flattop of $550 \mathrm{kA}$, injection of three $1.5 \mathrm{MW}, 80 \mathrm{keV} \mathrm{D}$ beam blips of $20 \mathrm{msec}$ width, HHFW injection of $2.5 \mathrm{MW}$ power, the neutron yield and the NPA signal at $E_{D}=100 \mathrm{keV}$. At bottom left is shown the NPA measurement of the 3-D energetic ion spectra extending out to $140 \mathrm{keV}$ corresponding to the three NB blips. The top left panel shows a time slice of the HHFW energetic tail spectrum extending from $80-140 \mathrm{keV}$ overlaid with $80 \mathrm{keV}$ NB slowing down spectrum in the absence of HHFW. The HHFW energetic tail forms in $5-10 \mathrm{msec}$, saturates in time during HHFW and appears to decay classically after HHFW turn off with a decay time of $\sim 20 \mathrm{msec}$, similar

S. S. Medley, et al. Contributed Paper to IAEA TCM on Energetic Particles in Magnetic Confinement Systems, Göteborg, Sweden, October 8-11, 2001 
to the decay of the NB slowing down distribution. As the HHFW injection power decreases, an energetic tail out to $140 \mathrm{keV}$ still forms but the time required for the tail to grow increases.

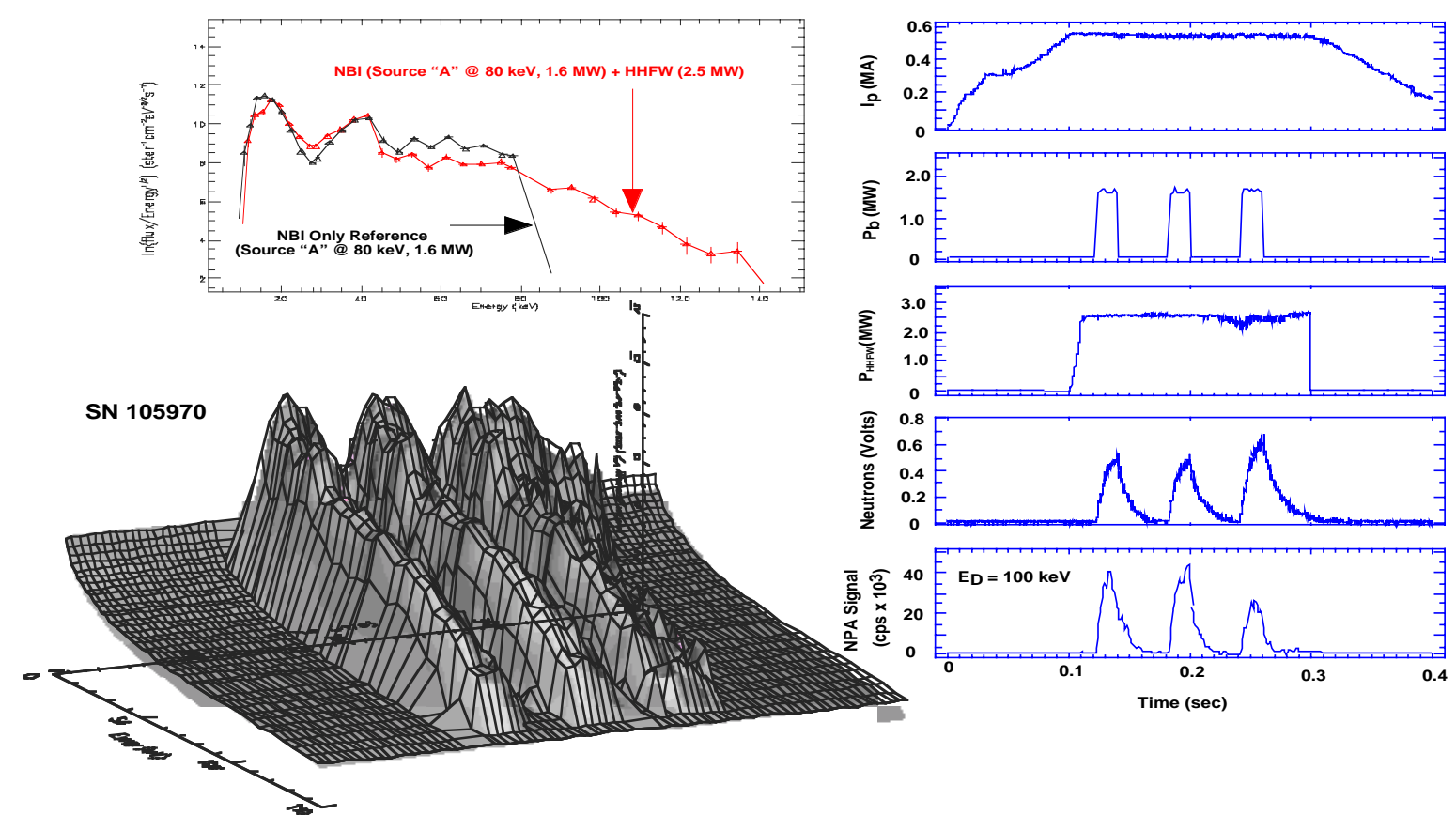

Figure 4. NPA Measurements of HHFW energetic ion tail formation in NSTX

The growth rate, amplitude and decay rate of the neutron yield all increase with application of HHFW during NBI which is consistent with the existence of the energetic ion tail observed. The tail is attributed to HHFW plus NBI fast ion interactions at $\omega / \Omega_{\mathrm{D}} \sim 9$.

\section{NPA Measurement of Ion Temperature}

Since NSTX uses deuterium for both the neutral beams and the plasma discharge, it is necessary to measure the spectra of the residual $\mathrm{H}^{+}$ions in order to obtain NPA ion temperature measurements. Quite recently, the NPA yielded the first time histories of $T_{i}$ on NSTX, an example of which is shown in Figure 5. The top panel shows the NPA fitted Maxwellian spectra for two times corresponding to the $T_{i}(t)$ measurements in the center panel obtained with a time resolution of $5 \mathrm{msec}$. The bottom panel shows waveforms for electron temperature and density from the multi-pulse Thomson scattering (MPTS) system as well as the injected neutral beam power, plasma current and a Mirnov coil trace. It can be seen that the ion and electron temperatures roll over at $\sim 0.22 \mathrm{sec}$ due to the onset of large MHD activity indicated by the Mirnov signal.

S. S. Medley, et al. Contributed Paper to IAEA TCM on Energetic Particles in Magnetic Confinement Systems, Göteborg, Sweden, October 8-11, 2001 

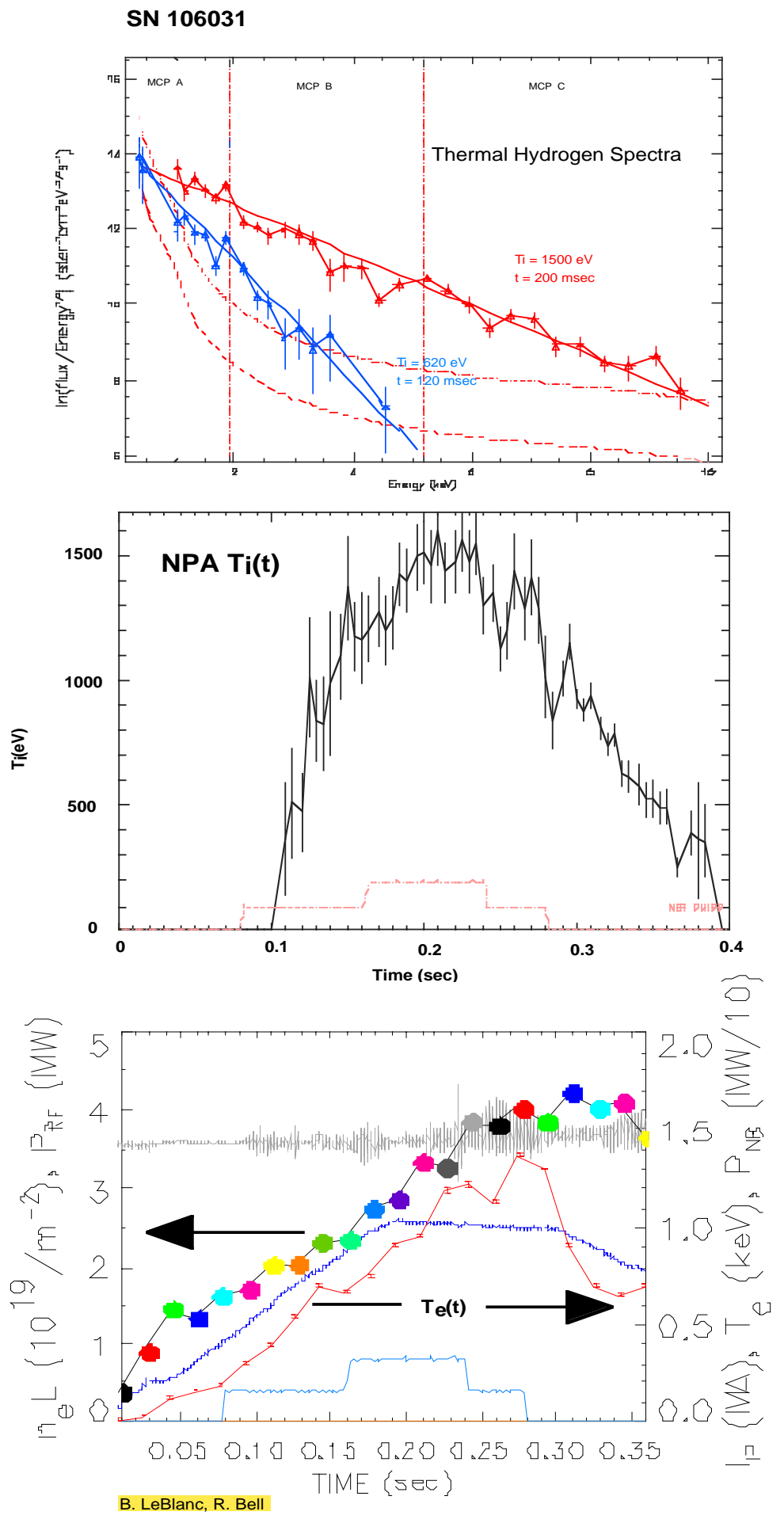

Figure 5.Typical NPA thermal hydrogen spectra (top panel) and ion temperature evolution (center panel).

S. S. Medley, et al. Contributed Paper to IAEA TCM on Energetic Particles in Magnetic Confinement Systems, Göteborg, Sweden, October 8-11, 2001 
The initial analysis of CHERS profiles during NB heating shows $T_{i}$ profiles that are typically hotter and broader than $T_{e}$ profiles [2]. Figure 6a shows the plasma current, NB power and a Mirnov coil trace. The vertical bar indicates the time of the CHERS measurement. NPA measurements are shown in Figure $6 \mathrm{~b}$ along with $T_{e}(0)$ from MPTS. Good agreement is found between the $T_{i}(0)$ from the CHERS profile (Figure $6 \mathrm{c}$ ) and $T_{i}$ from NPA taken at the same time. This agreement of the line-integral NPA measurements with the localized CHERS data is no doubt abetted by the broadness of the $T_{i}$ profiles. Further analysis is in progress to see if this agreement persists over a wide range of electron temperature and density profiles.

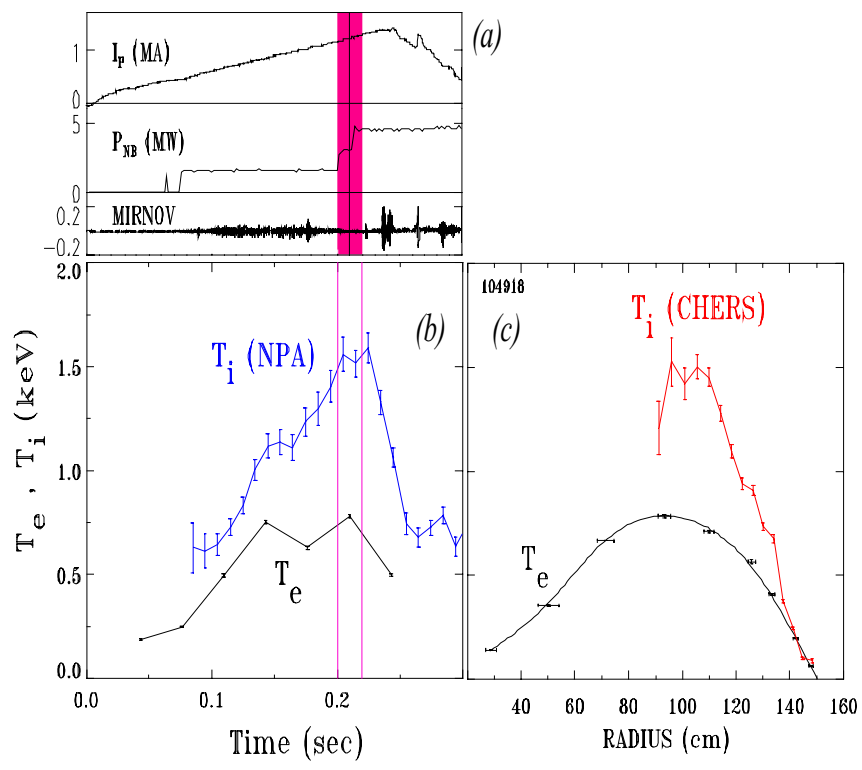

Figure 6. Comparison of temperature measurements from NPA, CHERS, and MPTS.

\section{Acknowledgements}

This work was supported by the United States Department of Energy under contract number DE-AC02-76CH03073.

\section{References}

[1] S. S. Medley, et al. Rev. Sci. Instrum. 69, 2651 (1998).

[2] R. E. Bell, et al. PPPL Report, PPPL-3591 (1998).

S. S. Medley, et al. Contributed Paper to IAEA TCM on Energetic Particles in Magnetic Confinement Systems, Göteborg, Sweden, October 8-11, 2001 


\section{External Distribution}

Plasma Research Laboratory, Australian National University, Australia

Professor I.R. J ones, Flinders University, Australia

Professor J oão Canalle, Instituto de Fisica DEQ/IF - UERJ , Brazil

Mr. Gerson O. Ludwig, Instituto Nacional de Pesquisas, Brazil

Dr. P.H. Sakanaka, Instituto Fisica, Brazil

The Librarian, Culham Laboratory, England

Library, R61, Rutherford Appleton Laboratory, England

Mrs. S.A. Hutchinson, JET Library, England

Professor M.N. Bussac, Ecole Polytechnique, France

Librarian, Max-Planck-Institut für Plasmaphysik, Germany

J olan Moldvai, Reports Library, MTA KFKI-ATKI, Hungary

Dr. P. Kaw, Institute for Plasma Research, India

Ms. P.J . Pathak, Librarian, Insitute for Plasma Research, India

Ms. Clelia De Palo, Associazione EURATOM-ENEA, I taly

Dr. G. Grosso, Instituto di Fisica del Plasma, Italy

Librarian, Naka Fusion Research Establishment, J AERI, J apan

Library, Plasma Physics Laboratory, Kyoto University, J apan

Research Information Center, National Institute for Fusion Science, J apan

Dr. O. Mitarai, Kyushu Tokai University, J apan

Library, Academia Sinica, Institute of Plasma Physics, People's Republic of China

Shih-Tung Tsai, Institute of Physics, Chinese Academy of Sciences, People's Republic of China

Dr. S. Mirnov, TRINITI, Troitsk, Russian Federation, Russia

Dr. V.S. Strelkov, Kurchatov Institute, Russian Federation, Russia

Professor Peter Lukac, Katedra Fyziky Plazmy MFF UK, Mlynska dolina F-2, Komenskeho Univerzita, SK-842 15 Bratislava, Slovakia

Dr. G.S. Lee, Korea Basic Science Institute, South Korea

Mr. Dennis Bruggink, Fusion Library, University of Wisconsin, USA

Institute for Plasma Research, University of Maryland, USA

Librarian, Fusion Energy Division, Oak Ridge National Laboratory, USA

Librarian, Institute of Fusion Studies, University of Texas, USA

Librarian, Magnetic Fusion Program, Lawrence Livermore National Laboratory, USA

Library, General Atomics, USA

Plasma Physics Group, Fusion Energy Research Program, University of California at San Diego, USA

Plasma Physics Library, Columbia University, USA

Alkesh Punjabi, Center for Fusion Research and Training, Hampton University, USA

Dr. W.M. Stacey, Fusion Research Center, Georgia Institute of Technology, USA

Dr. J ohn Willis, U.S. Department of Energy, Office of Fusion Energy Sciences, USA

Mr. Paul H. Wright, Indianapolis, Indiana, USA 
The Princeton Plasma Physics Laboratory is operated by Princeton University under contract with the U.S. Department of Energy.

\author{
Information Services \\ Princeton Plasma Physics Laboratory \\ P.O. Box 451 \\ Princeton, NJ 08543
}

Phone: 609-243-2750

Fax: 609-243-2751

e-mail: pppl_info@pppl.gov

Internet Address: http://www.pppl.gov 